\title{
Optimizing Induction Furnace Parameters Using TOPSIS
}

\section{Vivek R. Gandhewar}

Mechanical Engineering Department, Jawaharlal Darda Institute of Engineering and Technology, Yavatmal, Maharashtra, India

\section{ABSTRACT}

Among all the metal industries, the iron and steel industries are the most energy intensive sectors in India. Worldwide the use of induction furnaces in steel industries especially in foundries has increased exponentially. A great deal of research is dedicated to identify the factors that affect the performance of the furnace. It is observed that quantity of molten metal produced per batch, average time required for production per batch, electricity consumption per ton ,raw material in ratio, power supply on and off time, thickness of refractory lining are some of the crucial factors that are responsible for improving the productivity of Induction Furnace. This paper presents the results of a study where an attempt is made to optimize the specific energy consumption and alternatively productivity. The correlation between various parameters was found in order to optimize the results. To get the optimum results TOPSIS was applied. Finally, the results of the study confirm the common connotation that less specific energy consumption leads to more productivity. Academicians and practitioners could use the results as a guideline for studying effects of various induction furnace parameters

Keywords : Induction Furnace, Process parameters, productivity improvement, optimization, TOPSIS.

\section{INTRODUCTION}

From Indian perspective, the iron and steel industry are the most energy intensive sectors. These industries show wide use of Induction Furnaces (I.F.) for metal processing. The cannel function of IF is to melt and hold the molten metal. Literature shows that India is the only country in the world using induction furnaces on a large scale for production of steel (Dutta et al, 2004). Therefore there is a felt need to study and optimize the IF process parameters by means of a case study. Traditionally, melting process involves preparing the raw and loading, removing dirt and moisture, preheating the charge material and lastly introducing solid charge into the furnace system. The mostly used furnaces for melting in steel industries are, Cupola Furnace, Arc Furnace and Induction Furnace. Combustion furnaces and induction furnaces produce heat in two entirely different ways. In a combustion furnace, heat is created by burning a fuel such as coke, oil or natural gas. The burning fuel brings the interior temperature of the furnace above the melting point of the charge material placed inside. This heats the surface of the charge material, causing it to melt.

Induction furnaces produce their heat cleanly, without combustion. Alternating electric current from an induction power unit flows into a furnace and through a coil made of hollow copper tubing. This creates an electromagnetic field that passes through the refractory material and couples with conductive metal charge inside the furnace. This induces electric current to flow inside the metal charge itself, producing heat that rapidly causes the metal to melt. Although some furnace surfaces may 
become hot enough to present a burn hazard, with induction, you heat the charge directly, not the furnace.

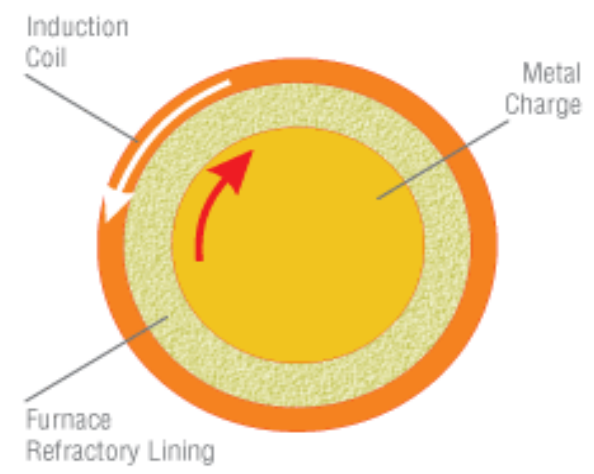

Fig. 1: Current flowing in one direction in the induction coil induces a current flow in the opposite direction in the metal charge. This current heats the metal and causes it to melt.

The literature review has been carried out for studying working principal of induction furnace, its construction and to account the various practices followed in induction furnace operations. The following few parameters have been identified as -

Raw material, Electrical Energy, Refractory Lining, Water, Molten Metal, Waste Heat, Total melting time, Slag, Slag Composition.

A pilot study has also been carried out in few industries in India. These industries are using induction furnaces as a part of the process. Following are the observations.

1. Mostly the raw material is charged as per the availability, and no particular sequence or proportion is followed. Scrap is not sorted or graded. While sampling, if carbon found more, the melter usually prefer to add sponge iron (low carbon) or proceed for the excessive stirring to reduce the carbon percentage. Both these results in greater specific energy consumption.
2. Heat tap to tap time is varying, though the output production is in the same range. The time for a heat also depends upon the type of scrap. Longer heat time translates into more power input for same amount of metal. This results in variation in specific energy consumption. (Fig.2)

3. While removing the slag the charging stops for nearly 3-5 minutes, the metal is overheated as scrap input is zero during this interval of 3-5 minutes, if the power supply is not lowered by operating the potentiometer, the molten metal starts boiling due to excessive temperature. In this case the melter turns off the power supply, this results in heat loss through water flowing through coil and increase in heat time and energy consumption.

5. If the slag sticks to the linings of furnace, it creates difficulty for charging the scrap, this also decrease the performance of the furnaces. While removing the slag built up from the walls the lining may also damaged.

\section{Specific Energy Consumption \& Molten Steel Quantity}

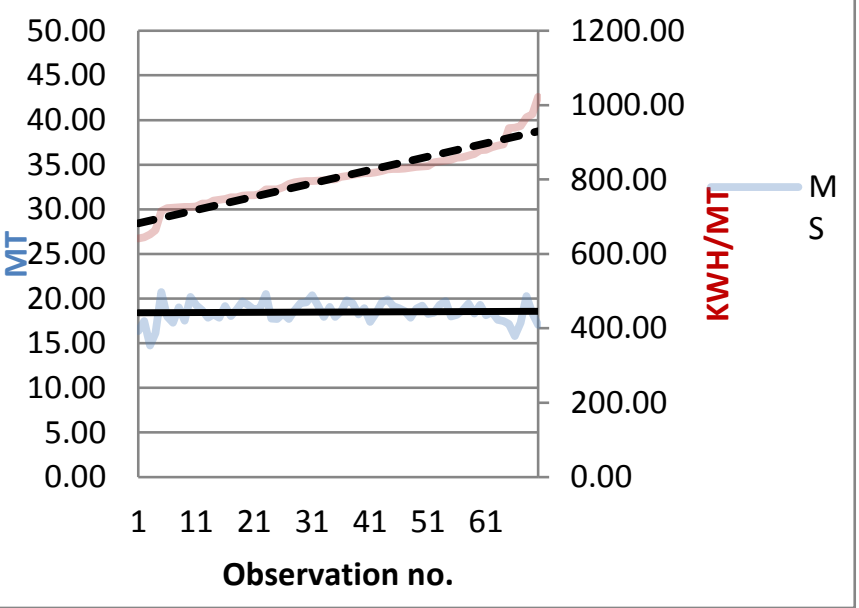




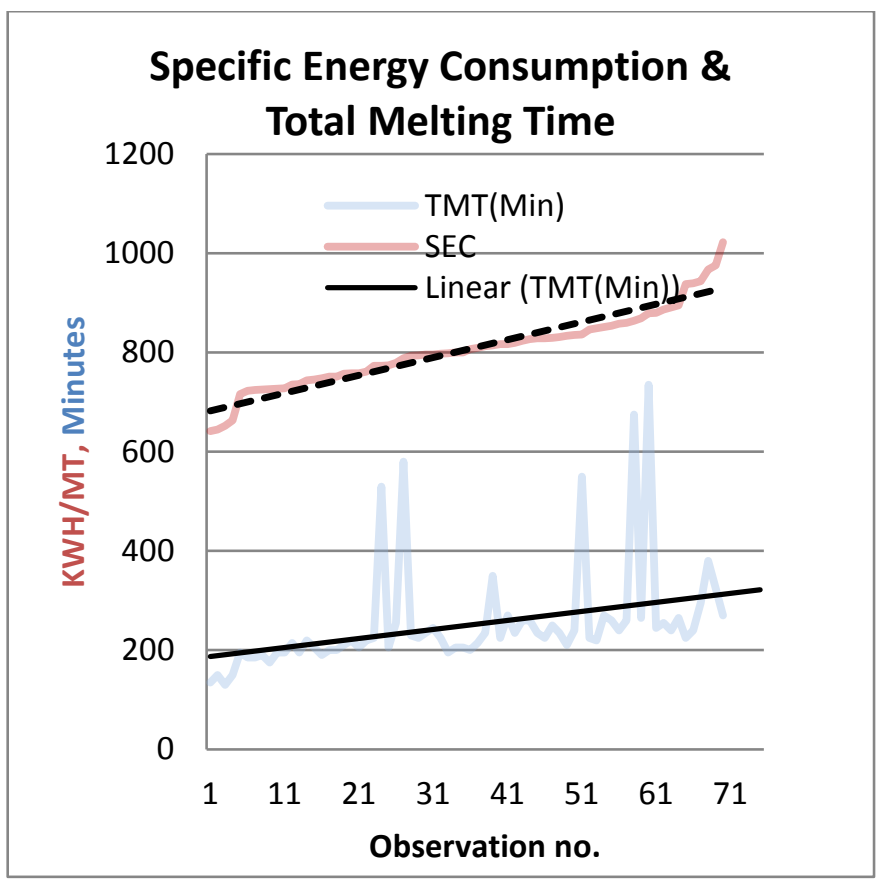

Fig 2. Graph showing relations of different parameters

6. Operating KW and KVA- It is observed that the furnace doesn't draw full power during the initial stage resulting in increased energy losses and more time is required for molten metal to form at the base of the crucible, which enables to speed up further melting.

7. Metal Quantity- It is observed that very frequently the level of molten metal at the time of tapping is nearly 25 to $28 \mathrm{cms}$. below the lip of crucible. This top layer of molten metal is very important. For getting the equivalent molten metal quantity it requires comparatively less time and energy because the melting is fast at this top level due to the fast heat transfer from molten bath. The specific energy consumption is more in case the metal is tapped before reaching at optimum level.

In this paper through the review of literature and visits to industries involved in steel melting and casting the few parameters are identified which play a role in performance of the Induction furnaces, these are
A. Power supply (Quantity of energy input) per cycle

B. Total melting time per cycle

C. Melt rate per cycle

D. Quantity of molten steel obtained per cycle

E. Specificic energy consumption per cycle

In industrial terms the cycle is termed as "heat".

The attempt is made to find the scope for optimization of these identified parameters. Various multi criteria decision making tools are available as described herewith

SAW(Simple Additive Weighing)

TOPSIS(Technique for Order Preference by Similirity to Ideal Solution)

ELECTRE(Elimination et Choice Translating Reality)

BAYESIAN network based framework

AHP(The Analytical Hierarchy Process)

SMART(The Simple Multi Attribute Rating

Technique)

ANP(Analytic Network Process)

Our aim is to optimize the operations of Induction Furnace in terms of the optimization of Specific Energy consumption. We used TOPSIS method for optimization, as this is the best suitable method for similar problems of Multi Criteria Decision Making(MCDM) problems.

The results are discussed with the help of sample output results of TOPSIS. Those in terms of the

\section{LITERATURE REVIEW}

Many researchers attempted to study the different aspects of Induction Furnace, the review of these work is carried out, this enables to understand the basic working and development in this area. 
Teece (1946),described that until about 1930, all special high-grade steels, such as high speed tool steels, corrosion resisting steels and magnet steels, were manufactured in crucible furnaces. This was the only suitable type of furnace available, as, if a gasfired open-hearth furnace or an electric-arc furnace were employed, the molten metal would be in intimate contact with the atmosphere and with the flames of combustion. The result would be that oxidation of the charge would take place to such a degree that its composition could not be accurately forecast. Not only would this make the manufacture of a special steel difficult, but also it would involve serious financial loss, as the alloying elements, such as nickel, tungsten and vanadium, which would be spoilt by oxidation, are very expensive. The crucible furnace, by exposing only a small surface area of the charge to the atmosphere, reduces the oxidation very considerably. As all the heat for melting the steel has to be supplied by conduction through the walls of the crucible, the weight of metal that can be melted in a crucible is necessarily limited. It was as an improvement on the crucible furnace that the highfrequnecy induction furnace was developed. The inductor of the furnace consists of a copper conductor wound in the form of a helical coil. As this coil carries a heavy current, and is heated also by its proximity to the molten metal, some form of cooling is necessary, and a water-cooled hollow conductor is used. This furnace coil is mounted in a box, approximately a cube, arranged to tilt about trunnions so that the molten metal can be poured into a ladle or ingot mould. The box must be designed to avoid extraneous eddy current heating. In small furnaces this is done by using a nonmagnetic and, as far as is practicable, non-metallic construction, and in the larger sizes where such a construction would not have sufficient mechanical strength, a steel framework is used, and a low reluctance return path for the flux is provided in the form of packets of laminations spaced around the coil. A refractory lining capable of holding the molten metal is necessary, and firebrick linings were found to be unsatisfactory. Ahmed et al (2009) also presented a design of coreless induction furnace for melting iron. Both mechanical and electrical requirements for induction furnace were considered. The geometrical parameters of the furnace such as diameter of melt, the height of melt, and diameter of coil were determined directly by the furnace capacity. The heat energy required to melt the charge material depends on the solid specific heat, latent heat of fusion, and liquid specific heat of the charge material. From which, the power required to melt the material was determined. The electrical parameters of the furnace such as number of turns of coil, inductance of the coil, resistance of the coil and the maximum flux density were determined based on transformer concept, where the furnace is represented by a transformer with $\mathrm{N}$ primary turns and one secondary turn that is short circuited. The design results were verified by comparing the design results with the corresponding ones of an actual induction furnace. The comparison shows good agreement between both results. Naranjo et al. (2005) found that Induction furnaces have increased in capacity to where modern high-powerdensity induction furnaces are competing successfully with cupola melting. There are fewer chemical reactions to manage in induction furnaces than in cupola furnaces, making it easier to achieve melt composition. However, induction melting is more sensitive to quality of charge materials when compared to cupola or electric arc furnace, limiting the types of scrap that can be melted. The inherent induction stirring provides excellent metal homogeneity. Induction melting produces a fraction of the fumes that result from melting in an electric arc furnace (heavy metal fumes and particulate emissions) or cupola (wide range of undesirable gaseous and particulate emissions as a result of the less restrictive charge materials). Bala (2005) also analyzed that the advancement of any nation technologically has been influenced and elevated by the extent to 
which it can usefully harness and convert its mineral resources. The productions of metal in foundries and in all human lives have also become a general practice. Different melting techniques are in practice with different energy sources. The cleanliness and availability of electrical energy sources in Nigeria is of paramount importance to its use in foundries, hence the need for this design. Mechanical and electrical requirements for induction furnace production are mainly focused .The mechanical aspect gives consideration to the geometrical components, cooling system, and the tilting mechanism. The electrical aspect deals with the furnace power requirement to make it functional. The design was achieved through consideration of relevant theories and their practical application, the various parameters considered are Geometrical parameters, Heat Energy and Electrical Parameters, Tilting Mechanism \& Velocity Ratio. Kaibicheva(1970) discussed about the lining process, before ramming the lining the inductor of the furnace is insulated with asbestos. The optimum thickness for a 4-ton furnace, for instance, is considered to be an insulating layer $10 \mathrm{~mm}$ thick.The most rational method is considered to be one involving the use of a lining from "dry" bodies, therefore the body before ramming is dried for $8 \mathrm{~h}$ at $150-180^{\circ} \mathrm{C}$ to a residual moisture content of $0.1 \%$. Wide use is made of all known methods of making crucibles: manual ramming, pneumatic, and vibrocompaction. With the manual method of preparing crucibles, the body is densified with a plate tamper having the shape of a blade. Grachev et al (1990) carried investigation of the process of overgrowth, during melting progressive overgrowth of the lining with reaction products occurs, which involves a significant decrease in the free surface of the crucible. The decrease in free surface has an unsatisfactory influence on the effectiveness of the furnace since it has a significant detremental effect on charging conditions, skimming off of the slag, and pouring of the finished metal. After a certain amount of time the overgrowth increases to such a degree that further use of the furnace becomes impossible. The overgrowth significantly reduces the interrepair cycle of furnace operation and reduces the technical and economic indices of melting. Bas'yas and Matyukin (1971) discussed about, the temperature cycle for induction, especially vacuum, furnaces has a considerable effect on the working time of the crucible. Both the overheating of the metal, which increases the sintering action on the lining, and also repeated cooling at a high rate causing cracking of the vitrified layer and penetration through the cracks of the material by molten metal, adversely affect the resistance. Information about the nature of the temperature distribution in the linings of induction furnaces is limited. A study of the temperature cycle in the lining of a laboratory rig reproducing the thermal conditions of the operation of the lining in crucible induction furnaces allowed the tracing of the nature of the change in the temperature as a function of the distance to the source of heat, the rate of change in its temperature, the heating or cooling time, and the influence of the cooler. Smith (1994) found that, the development of medium frequency power supplies has made coreless induction furnaces more acceptable in the aluminium industry through improvements in furnace design, operation and flexibility and also by virtue of reduced capital costs for a given melting rate. Operating parameters can now be better tailored to charge materials (frequency) and throughput (power density) to optimize both recovery and energy consumption. Pozdeev et al (1974) conduct a study and focused on, the possibility of using home scrap in the vacuum induction furnace production of low carbon stainless steel 000KhlSN12 with a limited oxygen, hydrogen, nitrogen, and nonmetallic inclusions content. The steel was made in a semicontinuous vacuum induction furnace of 0.5 tons capacity, using two methods: charge material melting, and blowing the melt with argon. Dutta et al.( 2004 ) investigated that main problems faced by steelmakers 
are short supply, fluctuating prices together with extremely heterogeneous nature and presence of tramp elements of steel scrap. Use of direct reduced iron (DRI) as a partial replacement to scrap, to some extent does help in overcoming this hurdle. However, unlike scrap and even pig iron, DRI is characterized by high porosity, low thermal and electrical conductivities which, in turn, poses problems in its melting. Attempts were made to study melting of DRI in a laboratory size induction furnace using molten steel bath as hot heel. The induction stirring accelerates the transfer of heat and promotes the melting of DRI. The effect of partial replacement of scrap by DRI on various melting parameters has been studied.

Some researchers contributed by finding some results by conducting the experiments, Kuvaldin \& Fedin (2008) developed the calculation algorithm of the melt surface shape of the induction crucible furnaces (ICF) taking into account the variable melt level in crucible. The special-purpose software package for calculation of the height and melt surface shape in ICF is also developed. The investigation results of the melt surface shape and its influence upon energy and electric characteristics of the ICF are presented. The height and melt surface shape can render the essential influence upon electric and energy parameters that particularly powerfully reveals upon full release of the melt from crucible walls at melting in ICF with cold crucible (so-called "electromagnetic" crucible). The significant influence of the melt shape on electric and energy characteristics of the unit with ICF is required to take into consideration at control systems development of the ICF. Umbrashko et al (2006) carried out the experimental measurements of the melt flow velocities, in a laboratory induction crucible furnace (ICF), where Wood's metal (50 pct bismuth, 25 pct lead, 12.5 pct tin, and 12.5 pct cadmium) is used as the model melt. Experimental results show that heat- and mass-transfer processes in recirculating turbulent flows, which comprise several vortexes of the mean flow, are significantly influenced by low-frequency large scale flow oscillations. The large eddy simulation (LES) model reproduces with good conformity not only these oscillations together with the dynamics of the macroscopic coherent structure, but also the turbulent energy transfer. Enokizono(1995) et al presents basic data on the effect of a high-frequency induction coil in the levitation-melting method. The buoyant force is measured with a digital balance under the constant $30 \mathrm{~kW}$ output, and the effect of the coil's position on the buoyancy is investigated experimentally. It has been shown that it might be possible to solve the problem of uniform heating in this system by controlling the rotation of ingot. Future work analyze the motion with the inclusion of temperature dependence in the three-dimensional numerical model. Henneberger and Obrecht(1994) investigated that, in induction furnaces, power losses from the eddy currents in the melt are used to heat the charged metal. Nearly all of the induced heating power is generated inside the melt within the small depth of penetration. On the other hand, the electromagnetic Lorentz forces on the molten metal cause heat transport by forced convection. The question is whether the influence of convection is strong enough to homogenize the temperature of the melt. They deals with a method to calculate numerically the steady state temperature distribution within the melt, taking into account the heat transport by conduction, convection and radiation. The calculations were done for a $800 \mathrm{~kg}$ steel furnace with a filling level of $125 \%$, an induced power of $50 \mathrm{k}$ $\mathrm{W}$ at $500 \mathrm{~Hz}$; any other combinations can be calculated. Lemire and. Biscaro (2004) conduct experiments and found that, the melting temperature of ferro-alloys is generally between $1400^{\circ} \mathrm{C}$ and $1600^{\circ} \mathrm{C}$. Induction and electric arc furnaces are technologies that are capable of melting fines. An electric arc furnace can easily treat metal fines, but 
the induction furnace is more appropriate for this case given the low tonnages involved. Firstly, charge characterization measurements were carried out and melt tests were run on a laboratory rig to validate the feasibility of melting fines by induction heating. The rig had an operating power of $10 \mathrm{~kW}$. This work demonstrated the feasibility of induction as a technology to melt ferro-alloy fines. Seminar report by The Energy conservation Center, Japan (ECC)(1998) focused on energy saving opportunity in induction furnace few of them are, Rated power is supplied to the furnace only when thickness of furnace refractory remains normal. Furnace power may be lowered when its inner diameter changes due to erosion of furnace wall or slag attached to the wall. Furnace wall damaged by erosion should be repaired to maintain the standard diameter in respect to thermal efficiency of the furnace.

Various tools are available to solve Multi Criteria Decision Making Problems, one of them is TOPSIS(Technique for Order Preference by Similirity to Ideal Solution). Some of the applications of TOPSIS method are discussed herewith.

Lotfi et al (2007) discussed the extension of the TOPSIS method for decision making problems with Fuzzy data. By this extension of TOPSIS method, an algorithm for determining the most preferable choice among all possible choices in the case of fuzzy data is presented. In this paper, a new method when the availability of information for decision environment is not exact is presented. Under such situation The Fuzzy TOPSIS method by considering the estimate data as fuzzy data help decision-makers to rank their choices. The interpretation of some factors as weight as economical component is not clear in general but in the numerical example interpretation are presented just for similar situation .Hao and Qing-sheng (2006) study the bidding evaluation a very important part in the invitation and submission of bids for manufacturing enterprises, they point out the defects of present bidding evaluation, and build a scientific evaluation indices model. The evaluating function is constructed by applying TOPSIS (technique for order preference by similarity to ideal solution), the option solution of evaluating function is solved as the optimism solution. A case study is carried out to find a new method to evaluate bidding bid in the manufacturing enterprises. The result shows TOPSIS is a good method in the manufacture enterprise invitation and submission of bids, and has great practical value. The scheme evaluation of the manufacture enterprise invitation and submission of bids is a typical example of multi-attribute decision. TOPSIS is one of most widely used methods to solve this problem. Using this method, we must notice two aspects: first, build a reasonable evaluation indices model; second, set the exact weight factors of every evaluation index. The practice proves that: TOPSIS method is a better method to evaluate the bidding of manufacturing. It not only improves present evaluation methods and avoids their simplification, but also reduces the influence of expert's subjective factors to the decision of scheme, At the same time this method can avoid the complex calculation and can be used easily in practice. Shyr and Kuo (2008) discuss the concept of airline Merging, now a days, more and more airlines have adopted various alliance strategies, such as code sharing, equity sharing, merging and acquisition to survive in the rigorously competitive market. To assess the effectiveness of code sharing and merging practices among airlines, they include major factors affecting the decisions of code sharing and merging into their model and propose the formulation and calibration procedures of payoff functions under various airline coalition scenarios. In the case study, TOPSIS is applied to assess the importance of factors in the decision making of code sharing and merging and to create a priority ranking of target airlines in the cooperative games. It is concluded that financial stability and 
profitability are the top two factors affecting merging decision while profitability is the only concern in the code sharing games. In addition, we found that Taiwan's domestic airlines would gain more profits through merging rather than code sharing while EVA and CAL could be the best target for merging. Chakladar and Chakraborty(2008) With the introduction and increased use of newer and harder materials such as titanium, stainless steel, highstrength temperature-resistant (HSTR) alloys, fibrereinforced composites, and ceramics in the aerospace, nuclear, missile, turbine, automobile, tool, and die making industries, a different class of machining processes has emerged. Instead of employing the conventional cutting tools, these non-traditional machining (NTM) processes use energy in its direct form to remove materials from the workpiece. Selection of the most suitable NTM process for machining a shape feature on a given work material requires consideration of severa factors. A combined method using the 'technique for order preference by similarity to ideal solution' (TOPSIS) and an analytical hierarchy process (AHP) is proposed to select the most appropriate NTM process for a specific work material and shape feature combination, while taking into account different attributes affecting the NTM process selection decision. This paper lso includes the design and development of a TOPSISAHP-method-based expert system that can automate the decision-making process with the help of a graphical user interface and visual aids. The expert system not only segregates the acceptable NTM processes from the list of the available processes, but also ranks them in decreasing order of preference. It also helps the user as a responsible guide to select the best NTM process by incorporating all the possible error trapping mechanisms.

\section{Methodology}

The review of literature are carried out and to study the prevailing practices visits are arranged to few steel industries in India. Those industries use Induction furnace for melting purpose. It is found that the following parameters are playing a role in performance of the Induction Furnace.

Raw material: Induction Furnaces are using Steel melting scrap, Sponge Iron \& Pig Iron/Cast Irons. On an average the ratio of these items is $40 \%$ sponge Iron $+10 \%$ Cast Irons or Pig Iron. The technology of melting these input materials varies according to the availability of raw materials and location of the plant and inputs of sponge iron consumed is as high as $85 \%$ as charge mix on bigger furnaces. (www.steelworld.com/smii.htm).

Power Supply: The information Brochure of an Inductotherm group company states that, an A.C.current from the transformer is fed to the rectifier of the furnaces electronic circuit. This converts A.C. to D.C, voltage is smoothed out by a D.C. choke, and then fed to the inverted section of the furnace. Here the D.C is converted to a high frequency A.C. current and this is fed to the coil. It is observed that though the rated power is supplied to the furnace, it always does not run at full power. The scrap compactness is responsible for this power, if the raw material is not compactly charged inside the furnace, it will not operate at supplied power. This results in a loss of time.

Refractory Lining: As per catalogue of Adore Multilane Products, the material used for lining is crushed quarts. This is a high purity silica material. The linings are of two types, acidic lining and basic lining. The first heat after lining is called sintering heat. This heat will take more time, because the power supplied is increased step by step so that the 
refractory material will set properly. With continuous use it starts eroding and after a certain time it need patching or lining again.

Water: The cooling system is a through-one-wayflow system with the tubular copper coils connected to water source through flexible rubber hoses. The inlet is from the top while the outlet is at the bottom. The cooling process is important because the circuit of the furnace appears resistive, and the real power is not only consumed in the charged material but also in the resistance of the coil. This coil loss as well as the loss of heat conducted from the charge through the refractory crucible requires the coil to be cooled with water as the cooling medium to prevent undue temperature rise of the copper coils.

Molten Metal : The molten metal is the desired output of the Induction furnace. The quantity depends upon the capacity of the furnace, and the quality depends upon the raw material and alloy composition. The tapping temperature depends upon the type of steel, as well as the distance of location of end use of the molten metal. If the furnace is operated at desired working conditions, the molten metal quantity will obtained as per specification of the furnace. In case of some adverse situation the quantity will decreased. Eg. If time constraint for heat is there, and raw material is not of desired quality, in that case the quantity of molten metal will be less. Similarly in sintering heat the furnace diameter is at least position, so quantity of molten metal is less while the time of the heat will be more, this may result in more specific energy consumption.

Waste Heat: The surface of the molten metal bath is exposed to atmosphere. This results in the major thermal energy loss through radiation. The Coils of furnace are water cooled this also results in heat loss. Furnace cover is used in some cases, but in case of continuous charging practice the use of furnace cover is not possible. If the furnace is off during the operation, then also the water flow through the copper induction coils is uninterrupted. This results in heat loss and in reducing the molten metal temperature. To gain the temperature, again the electrical energy is needed. The off time or holding time results in great energy loss.

Slag : During the operation of electric induction melting furnaces, non metallics are produced from the various sources described earlier. Depending on the specific process being used and the type of iron or steel being melted, the composition of the slag will vary. The cleanliness of the metallic charge, often consisting of sand encrusted gates and risers from the casting process or rust and dirt encrusted scrap, has a significant effect on the type of slag formed during the melting operation. The composition of insoluble build-up will be more complex if the slag reacts with the refractory employed in the melting furnace.

Slag Composition: Naranjo et al(2005) described that, the composition of furnace and ladle slags is often very complex. The slags that form in electric furnace melting are the results of complex reactions between silica (adhering sand on casting returns or dirt), iron oxide from steel scrap, other oxidation bi products from melting, and reactions with refractory linings. The resulting slag will thus consist of a complex liquid phase of oxides of iron, manganese, magnesium and silicon, silicates and sulfides plus a host of other compounds, which may include alumina, calcium oxides and sulfides, rare earth oxides and sulfides and spinels and fosterites.

Heat Time: The time required to complete one cycle of operation is called Heat Time.

Total Melting time or Tap to tap time: The time between two tappings, this also includes the furnace time, breakdown time as well as holding time. In total 
melting time, if these non productive times are more, it results in great loss in terms of waste heat as well as specific energy consumption.

Specific Energy Consumption(SEC).

Total Melting Time (TMT):

Melt Rate (MR):

Number of heats are observed and noted the Energy Consumption (KWh): corresponding readings for the following major Quantity Of Molten Steel (MS): parameters.

Table 1: Observations for 5 parameters of Induction Furnace.

$\begin{array}{cccccccc}\text { Date } & \text { F/C- } & \text { Heat } & \text { SEC } & \text { TMT } & \text { MR } & \text { EC } & \text { MS } \\ & \text { No. } & \text { No } & (\text { KWH/MT }) & (\text { Min }) & (\text { Kg/Min }) & \text { KWh } & (\text { MT) } \\ \text { 01/10/2009 } & \text { A } & 4522 & 856.89 & 1095 & 16.69 & 15664 & 18.28 \\ 01 / 10 / 2009 & \text { A } & 4524 & 751.75 & 200 & 90.15 & 13554 & 18.03 \\ 04 / 10 / 2009 & \text { A } & 4534 & 788.26 & 580 & 30.53 & 13960 & 17.71 \\ 04 / 10 / 2009 & \text { A } & 4535 & 735.19 & 215 & 86.98 & 13748 & 18.70 \\ 04 / 10 / 2009 & \text { A } & 4536 & 773.83 & 205 & 86.49 & 13720 & 17.73 \\ 04 / 10 / 2009 & \text { A } & 4537 & 757.97 & 205 & 91.46 & 14212 & 18.75 \\ 04 / 10 / 2009 & \text { A } & 4538 & 757.80 & 220 & 87.45 & 14580 & 19.24 \\ 05 / 10 / 2009 & \text { A } & 4539 & 757.01 & 210 & 93.71 & 14898 & 19.68 \\ 05 / 10 / 2009 & \text { A } & 4540 & 747.73 & 190 & 100.89 & 14334 & 19.17 \\ 07 / 10 / 2009 & \text { A } & 4555 & 773.34 & 530 & 33.55 & 13750 & 17.78 \\ 07 / 10 / 2009 & \text { A } & 4556 & 735.87 & 195 & 91.49 & 13128 & 17.84 \\ 08 / 10 / 2009 & \text { A } & 4557 & 723.21 & 185 & 97.14 & 12996 & 17.97 \\ 08 / 10 / 2009 & \text { A } & 4558 & 726.56 & 175 & 100.06 & 12722 & 17.51 \\ 08 / 10 / 2009 & \text { A } & 4559 & 751.76 & 200 & 93.90 & 14118 & 18.78 \\ 08 / 10 / 2009 & \text { A } & 4560 & 726.87 & 195 & 103.64 & 14690 & 20.21 \\ 13 / 10 / 2009 & \text { A } & 4591 & 846.74 & 1045 & 17.03 & 15072 & 17.80 \\ 13 / 10 / 2009 & \text { A } & 4592 & 761.12 & 220 & 86.27 & 14446 & 18.98 \\ 13 / 10 / 2009 & \text { A } & 4593 & 743.72 & 220 & 82.86 & 13558 & 18.23 \\ 13 / 10 / 2009 & \text { A } & 4594 & 794.46 & 225 & 86.62 & 15484 & 19.49 \\ 13 / 10 / 2009 & \text { A } & 4595 & 727.44 & 195 & 98.67 & 13996 & 19.24 \\ 13 / 10 / 2009 & \text { A } & 4596 & 725.66 & 190 & 100.11 & 13802 & 19.02 \\ 14 / 10 / 2009 & \text { A } & 4597 & 715.68 & 195 & 106.31 & 14836 & 20.73 \\ 14 / 10 / 2009 & \text { A } & 4598 & 773.18 & 225 & 91.16 & 15858 & 20.51 \\ \text { 20/10/2009 } & \text { A } & 4623 & 836.12 & 550 & 33.22 & 15276 & 18.27 \\ \text { 21/10/2009 } & \text { A } & 4625 & 745.77 & 205 & 87.07 & 13312 & 17.85 \\ \text { 21/10/2009 } & \text { A } & 4626 & 663.56 & 150 & 107.40 & 10690 & 16.11 \\ \text { 21/10/2009 } & \text { A } & 4627 & 652.24 & 130 & 113.38 & 9614 & 14.74 \\ \text { 22/10/2009 } & \text { A } & 4628 & 724.19 & 185 & 93.41 & 12514 & 17.28 \\ \text { 22/10/2009 } & \text { A } & 4629 & 641.51 & 135 & 121.33 & 10508 & 16.38 \\ \text { 22/10/2009 } & \text { A } & 4630 & 644.57 & 150 & 116.67 & 11280 & 17.50 \\ 07 / 03 / 2010 & \text { A } & 5260 & 863.85 & 675 & 28.77 & 16776 & 19.42\end{array}$




\begin{tabular}{|c|c|c|c|c|c|c|c|}
\hline 07/03/2010 & A & 5261 & 835.12 & 240 & 79.96 & 16026 & 19.19 \\
\hline 07/03/2010 & $\mathrm{A}$ & 5262 & 793.15 & 230 & 81.22 & 14816 & 18.68 \\
\hline 08/03/2010 & A & 5264 & 846.61 & 225 & 81.82 & 15586 & 18.41 \\
\hline 08/03/2010 & A & 5265 & 823.27 & 260 & 75.38 & 16136 & 19.60 \\
\hline $12 / 03 / 2010$ & A & 5266 & 967.19 & 380 & 53.42 & 19634 & 20.30 \\
\hline $12 / 03 / 2010$ & A & 5267 & 778.81 & 255 & 71.80 & 14260 & 18.31 \\
\hline $14 / 03 / 2010$ & A & 5286 & 878.63 & 735 & 26.23 & 16940 & 19.28 \\
\hline $15 / 03 / 2010$ & A & 5287 & 860.03 & 260 & 71.88 & 16074 & 18.69 \\
\hline $15 / 03 / 2010$ & A & 5288 & 894.62 & 265 & 65.96 & 15638 & 17.48 \\
\hline $15 / 03 / 2010$ & A & 5289 & 797.29 & 225 & 85.42 & 15324 & 19.22 \\
\hline $15 / 03 / 2010$ & A & 5290 & 851.07 & 270 & 72.96 & 16766 & 19.70 \\
\hline $15 / 03 / 2010$ & A & 5291 & 800.22 & 205 & 87.46 & 14348 & 17.93 \\
\hline $15 / 03 / 2010$ & A & 5292 & 800.00 & 205 & 93.07 & 15264 & 19.08 \\
\hline $16 / 03 / 2010$ & A & 5293 & 809.69 & 215 & 92.14 & 16040 & 19.81 \\
\hline 23/03/2010 & A & 5334 & 1022.25 & 270 & 63.26 & 17460 & 17.08 \\
\hline $23 / 03 / 2010$ & A & 5335 & 939.71 & 240 & 65.79 & 14838 & 15.79 \\
\hline $23 / 03 / 2010$ & A & 5336 & 886.18 & 255 & 72.63 & 16412 & 18.52 \\
\hline $23 / 03 / 2010$ & A & 5337 & 938.23 & 225 & 76.27 & 16100 & 17.16 \\
\hline $24 / 03 / 2010$ & A & 5339 & 975.60 & 325 & 56.49 & 17912 & 18.36 \\
\hline $24 / 03 / 2010$ & A & 5340 & 795.92 & 235 & 83.40 & 15600 & 19.60 \\
\hline $24 / 03 / 2010$ & A & 5341 & 848.76 & 220 & 87.82 & 16398 & 19.32 \\
\hline $24 / 03 / 2010$ & A & 5342 & 834.04 & 210 & 89.81 & 15730 & 18.86 \\
\hline $25 / 03 / 2010$ & A & 5343 & 826.83 & 260 & 76.54 & 16454 & 19.90 \\
\hline $25 / 03 / 2010$ & A & 5344 & 828.32 & 235 & 81.45 & 15854 & 19.14 \\
\hline $25 / 03 / 2010$ & A & 5345 & 796.27 & 245 & 83.18 & 16228 & 20.38 \\
\hline $25 / 03 / 2010$ & A & 5346 & 891.08 & 240 & 73.38 & 15692 & 17.61 \\
\hline 05/04/2010 & A & 5409 & 944.06 & 295 & 58.54 & 16304 & 17.27 \\
\hline 05/04/2010 & A & 5410 & 880.02 & 245 & 73.96 & 15946 & 18.12 \\
\hline 05/04/2010 & A & 5411 & 831.30 & 235 & 75.87 & 14822 & 17.83 \\
\hline 05/04/2010 & A & 5412 & 853.64 & 260 & 69.27 & 15374 & 18.01 \\
\hline 05/04/2010 & A & 5413 & 858.35 & 240 & 75.83 & 15622 & 18.20 \\
\hline 05/04/2010 & A & 5414 & 817.01 & 270 & 64.44 & 14216 & 17.40 \\
\hline 06/04/2010 & A & 5415 & 814.58 & 350 & 52.14 & 14866 & 18.25 \\
\hline 06/04/2010 & A & 5416 & 819.15 & 235 & 78.21 & 15056 & 18.38 \\
\hline 06/04/2010 & A & 5417 & 869.07 & 265 & 69.17 & 15930 & 18.33 \\
\hline 06/04/2010 & A & 5418 & 806.79 & 200 & 92.75 & 14966 & 18.55 \\
\hline 06/04/2010 & A & 5419 & 816.71 & 225 & 84.04 & 15444 & 18.91 \\
\hline 07/04/2010 & A & 5420 & 828.81 & 225 & 84.22 & 15706 & 18.95 \\
\hline 07/04/2010 & A & 5421 & 812.62 & 235 & 82.94 & 15838 & 19.49 \\
\hline 07/04/2010 & A & 5422 & 798.44 & 195 & 92.10 & 14340 & 17.96 \\
\hline 07/04/2010 & A & 5423 & 829.71 & 250 & 74.32 & 15416 & 18.58 \\
\hline
\end{tabular}


Various tools are available to solve Multi Criteria Decision Making Problems, few of them are: SAW(Simple Additive Weighing)

TOPSIS(Technique for Order Preference by Similirity to Ideal Solution)

ELECTRE(Elimination et Choice Translating Reality)

BAYESIAN network based framework

AHP(The Analytical Hierarchy Process)

SMART(The Simple Multi Attribute Rating Technique)

ANP(Analytic Network Process)

Our aim is to optimize the operations of Induction Furnace in terms of the optimization of Specific Energy consumption. We used TOPSIS method for optimization, as this is the best suitable method for similar problems of Multi Criteria Decision Making(MCDM).

Topsis Method:

Step 1 : Calculate normalized matrix: By normalizing the original data, we get the normalized ratings rij and build the following normalized matrix.

$$
r_{i j}=x_{i j} / \sqrt{\sum_{i=0}^{m} x^{2} i j}, i=1,2, \ldots, m ; j=1,2, \ldots \ldots, n
$$

Step 2 : Calculate weighted normalized ratings: The weight normalized value vij is calculated as

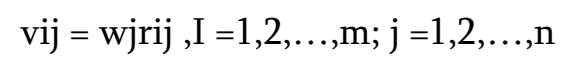

where wj is the weight of the jth attribute.

There are several ways to set the weight factors like Point Method, fuller's Method, Satty's method.

Step 3 : Identify ideal and non-ideal solutions:

The $\mathrm{A}^{*}$ and $\mathrm{A}^{-}$-are calculated in terms of the weight normalized values, which is defined as

$$
\begin{aligned}
& A^{*}=\left\{\left(\max _{i j} \mid j \in j_{1}\right),\left(\min _{i j} \mid j \in J_{2}\right), i=1,2, \ldots, m\right\} \\
& \mathrm{i} \\
& =\left\{v_{1}^{*}, v_{2}{ }^{*}, \ldots, v_{j}{ }^{*}, \ldots \ldots, v_{n}{ }^{*}\right\} \\
& A^{-}=\left\{\left(\operatorname{minv}_{i j} \mid j \in j_{1}\right),\left(\max _{i j} \mid j \in J_{2}\right), i=1,2, \ldots, m\right\} \\
& =\left\{v_{1}{ }^{-}, v_{2}{ }^{-}, \ldots ., v_{j}{ }^{-}, \ldots \ldots, v_{n}{ }^{-}\right\}
\end{aligned}
$$

Where $J_{1}$ is a set of benefit attributes, which means the ideal solution of $i^{\text {th }}$ attribute. $J_{2}$ is a set of cost attributes which means the non-ideal solution of the $i^{\text {th }}$ attribute. The larger the benefit attributes is, the greater preference it has such as: Melt rate, Quantity of Molten Steel. The smaller the cost attributes is, the greater its preference is, such as: Time, Energy Consumption. 
Step 4 : Calculate the indicate distances:

Calculation of the indicate distances between the ideal and the non-ideal solutions can be carried out by ndimensional Euclidean distance. The distances from each indicate to the ideal solution $A^{*}$ is $S^{*}$,and from the non-ideal solution $A^{-}$is $S^{-}$, the formula is as follows.

$$
\begin{aligned}
& S^{*}=\sqrt{\left(\sum_{j=1}^{n}\left(V_{i j}-V_{i j}^{*}\right)^{2}\right)}, i=1,2, \ldots . . m . \\
& S^{-}=\sqrt{\left(\sum_{j=1}^{n}\left(V_{i j}-V_{i j}^{-}\right)^{2}\right)}, i=1,2, \ldots . . m .
\end{aligned}
$$

Where $V_{j}^{*}$ and $V_{j}^{-}$means the distances from $j^{\text {th }}$ attribute to the ideal and non-ideal solutions. $V_{i j}$ is the weight normalized value of the $j^{\text {th }}$ attribute. $S^{*}$ means the degree of similarity between every evaluate solution to the ideal solution, the smaller $S^{*}$ is ,the smaller distances to the ideal solution, the better the solution is.

Step 5 : Calculate the relative closeness of the ideal solution:

$$
C_{i}^{*}=S_{i}^{-} /\left(S_{1}^{*}+S_{i}^{-}\right), i=1,2, \ldots \ldots \ldots, m
$$

Note that $0 \leq C_{i}^{*} \leq 1$,

When $C_{i}^{*}=0, A_{1}=A^{-}$; when $C_{1}^{*}=1, A_{1}=A^{*}$

Rank preference order according to $C^{*}$ :

Rank alternatives according to $C^{*}$ in descending order. The larger $C^{*}$ is ,the better the solution is,and the solution which has the maximum $C^{*}$ is the best.

Case Study:

Through experimentation the data is collected from a medium scale steel industry using the Induction Furnace for steel melting, the specification of the furnace is:

Make- Danilee

Capacity- 15 tonns

Type- Medium frequency.

The aim is optimization of the Induction Furnace performance, in terms of Specific Energy Consumption. Generalized form of this aim can be tabulated as.

Table 2: Parameters and desired actions

\begin{tabular}{|c|c|c|c|c|c|}
\hline Parameter & SEC & TMT & MR & KWH & MS \\
\hline Action & Minimize & Minimize & Maximize & Minimize & Maximize \\
\hline
\end{tabular}


Considering the noted parameter as criteria and no. of heat as alternatives, the number of readings are taken. These readings are feed to the TOPSIS software provide the weight factor for each criteria and we used Satty's Method for weighing the criteria.

Satty's Method:

Satty's Triangle:-By finding the co-relation of criteria with each other, decide the scale for individual weight factor

Table 3: Scaling of co relation factor

\begin{tabular}{|c|c|c|c|c|c|c|c|c|c|}
\hline $\begin{array}{c}\text { Range of co } \\
\text { relation factor }\end{array}$ & 0.8 & 0.6 & 0.4 & 0.2 & 0.2 & -0.2 & -0.4 & -0.6 & -0.8 \\
& 1 & 0.8 & 0.6 & 0.4 & -0.2 & -0.4 & -0.6 & -0.8 & -1.0 \\
\hline Rank & 9 & 8 & 7 & 6 & 5 & 4 & 3 & 2 & 1 \\
\hline
\end{tabular}

With respect to the co-relation value the corresponding value of rank is placed in Satty's Triangle as below.

Table 4: Satty's triangle

\begin{tabular}{c|c|c|c|c|}
\cline { 2 - 5 } $\begin{array}{c}\text { Criteria } \\
\text { Criteria } \\
\text { Weight Factor }\end{array}$ & SEC & SEC & SEC & SEC \\
\cline { 2 - 5 } & TMT & MR & KWH & MS \\
\cline { 2 - 5 } & 6 & 2 & 9 & 5 \\
\hline
\end{tabular}

\begin{tabular}{c|c|c|c|}
\cline { 2 - 4 } Criteria & TMT & TMT & TMT \\
\cline { 2 - 4 } Criteria & MR & KWH & MS \\
\cline { 2 - 4 } Weight Factor & 1 & 6 & 5 \\
\cline { 2 - 4 } & &
\end{tabular}

\begin{tabular}{|c|c|c|}
\hline Criteria & MR & MR \\
\hline Criteria & KWH & MS \\
\hline Weight Factor & 3 & 5 \\
\hline
\end{tabular}

\begin{tabular}{c|c|}
\cline { 2 - 2 } Criteria & $\mathrm{KWH}$ \\
\cline { 2 - 2 } Criteria & $\mathrm{MS}$ \\
\cline { 2 - 2 } Weight Factor & 7 \\
\cline { 2 - 2 } &
\end{tabular}

After putting these values it gives Satty's Matrix, this results in the values of weights for each criteria, Table 5: Values of Weights for different criteria

\begin{tabular}{|c|c|c|c|c|c|}
\hline Criteria & SEC & TMT & MR & KWH & MS \\
\hline Weights & 0.4897 & 0.19198 & 0.20819 & 0.07423 & 0.03590 \\
\hline
\end{tabular}


After providing the weights, the method is to be selected as TOPSIS and from report option we can get the required reports. Through this analysis we get the rank of the heat as per the criteria provided by us.

\section{Results}

In this case study we get the results which are noted as sample in the table below.

Table 6: Ranking obtained from TOPSIS

Results from TOPSIS

\begin{tabular}{|c|l|r|}
\hline Rank & Heat No. & R.U.Value \\
\hline 1 & 4629 & 0.98273 \\
\hline 2 & 4630 & 0.96798 \\
\hline 3 & 4627 & 0.96381 \\
\hline 20 & 4537 & 0.70192 \\
\hline 21 & 4538 & 0.69711 \\
\hline 22 & 4592 & 0.68946 \\
\hline 40 & 5416 & 0.55602 \\
\hline 41 & 5414 & 0.54959 \\
\hline 42 & 5265 & 0.54071 \\
\hline 60 & 5336 & 0.40924 \\
\hline 61 & 4591 & 0.40548 \\
\hline 62 & 5346 & 0.40334 \\
\hline 70 & 5339 & 0.23403 \\
\hline 71 & 5266 & 0.23208 \\
\hline 72 & 5334 & 0.21186 \\
\hline
\end{tabular}

\section{CONCLUSION}

According to TOPSIS ranking the corresponding values of criteria are noted. It is found that the Specific Energy Consumption is a major role player in optimization of the Induction Furnace. Few heats are there having more molten metal than the rank 1 heat but our sole aim is not to increase the output only, but optimization of overall performance of the furnace. In heat no 4627 the Energy Consumption is found less than the Rank 1 heat (no.4629) but simultaneously the molten steel quantity is also less.
Values of criteria for corresponding heat no.

\begin{tabular}{|c|c|c|c|c|}
\hline SEC & TMT & MR & KWH & MS \\
\hline 641.51 & 135 & 121.33 & 10508 & 16.38 \\
\hline 644.57 & 150 & 116.67 & 11280 & 17.50 \\
\hline 652.24 & 130 & 113.38 & 9614 & 14.74 \\
\hline 757.97 & 205 & 91.46 & 14212 & 18.75 \\
\hline 757.80 & 220 & 87.45 & 14580 & 19.24 \\
\hline 761.12 & 220 & 86.27 & 14446 & 18.98 \\
\hline 819.15 & 235 & 78.21 & 15056 & 18.38 \\
\hline 817.01 & 270 & 64.44 & 14216 & 17.40 \\
\hline 823.27 & 260 & 75.38 & 16136 & 19.60 \\
\hline 886.18 & 255 & 72.63 & 16412 & 18.52 \\
\hline 846.74 & 1045 & 17.03 & 15072 & 17.80 \\
\hline 891.08 & 240 & 73.38 & 15692 & 17.61 \\
\hline 975.60 & 325 & 56.49 & 17912 & 18.36 \\
\hline 967.19 & 380 & 53.42 & 19634 & 20.30 \\
\hline 1022.25 & 270 & 63.26 & 17460 & 17.08 \\
\hline
\end{tabular}

After taking into considering all the operating conditions of furnace, we conclude that if these conditions are kept in allowable range, the Furnace will give the optimum performance.

\section{REFERENCES}

[1]. Baake, E., Nacke, B., Bernier, F. , Vogt, M. and Muhlbauer, A. ,2003. Experimental and numerical investigations of the temperature field and melt flowin the induction furnace with cold crucible, COMPEL: The International Journalfor Computation and Mathematics in Electrical and 
Electronic Engineering Vol. 22 No. 1, 2003 pp. 88-97

[2]. Bala, K. C., 2005.Design Analysis of an Electric Induction Furnace for Melting Aluminum Scrap , AU J.T. 9(2): 83-88 (Oct. 2005)

[3]. Chakladar, N. D. and Chakraborty, S. , A combined TOPSIS-AHP-method-based approach for non-traditional machining processes selection, Proceedings of IMechE Vol. 222 Part B: J. Engineering Manufacture, August 2008.

[4]. Dutta, S.K., Lele, A.B. and Pancholi, N.K.,2004, Studies On Direct Reduced Iron Melting In Induction Furnace Trans. Indian Inst. Met. Vol.57, No. 5, October 2004, pp. 467-473.

[5]. Hao, LI \& Qing-sheng, XIE ,Application of Topsis in the bidding evaluation of manufacturing enterprises, Proceedings of eENGDET2006 5th International Conference on e-Engineering \& Digital Enterprise Technology 16th -18th August, 2006, Guiyang, China, , p 184-188.

[6]. HU, HONGFA and ARGYROPOULOS, STAVROS A.,1997. Mathematical Simulation and Experimental Verification of Melting Resulting from the Coupled Effect of Natural Convection and Exothermic Heat of Mixing, Metallurgical And Materials Transactions B Volume 28b, February 1997-147

[7]. Lotfi, F. Hosseinzadeh, Allahviranloo, T., Jondabeh, M. Alimardani, and Kiani, N. A. , A New Method for Complex Decision Making Based on TOPSIS for Complex Decision Making Problems with Fuzzy Data, Applied Mathematical Sciences, Vol. 1, 2007, no. 60, p 2981 - 2987.

[8]. Naranjo, Robert D. , Kwon, Ji-Yea, Majumdar, Rajita and Choate, William T.,2005. Advanced Melting Technologies: Energy Saving Concepts and Opportunities for the Metal Casting Industry. Report prepared for ITP Metal Casting, by BCS, Incorporated 5550 Sterrett Place, Suite
306 Columbia, MD 21044 www.bcshq.com,Nov2005

[9]. Naro, R. L. (Rod), 2003, Control of Slag and Insoluble Build-up in Melting Furnaces, International Iron Melting Conference Orlando, Florida, November 4, 2003

[10]. Seminar On Energy Conservation In Iron Casting Industry1998 Sponsored by United Nations Industrial Development Organization (UNIDO) and Ministry of International Trade and Industry (MITI), Japan Hosted by Ministry of Industry Socialist Republic of Viet Nam Organized by The Energy conservation Center, Japan (ECC) 1998 Hanoi

[11]. Shyr, Oliver F. and Kuo, Yi-Pin, APPLYING TOPSIS AND COOPERATIVE GAME THEORY IN AIRLINE MERGING AND COALITION DECISIONS, Journal of Marine Science and Technology, Vol. 16, No. 1, 2008 , p 8-18.

[12].Umbrashko, A. ,Baake, E., Nacke, B. .2005. Experimental investigations and numerical modelling of the melting process in the cold crucible, COMPEL: The International Journal for Computation and Mathematics in Electrical and Electronic Engineering Vol. 24 No. 1, 2005 pp. 314-323

[13]. Information Brochure of Inductotherm Safety Information: An Inductotherm Group Company.

[14]. Catalogue of Adore Multilane Products: Manufacturer of Ramming Mass.

[15]. www.steelworld.com/smii.htm

\section{Cite this article as :}

Vivek R. Gandhewar, "Optimizing Induction Furnace Parameters Using TOPSIS", International Journal of Scientific Research in Science and Technology (IJSRST), Online ISSN : 2395-602X, Print ISSN : 23956011, Volume 7 Issue 2, pp. 518-533, March-April 2020. Available at doi : https://doi.org/10.32628/IJSRST207270 Journal URL : http://ijsrst.com/IJSRST207270 